\title{
Influence of prenatal nutrition and obesity on tissue specific fat mass and obesity-associated (FTO) gene expression
}

\author{
S P Sébert, M A Hyatt, L L Y Chan, M Yiallourides, H P Fainberg, N Patel, D Sharkey, T Stephenson, \\ S M Rhind ${ }^{2}$, R C Bell ${ }^{3}$, H Budge, D S Gardner ${ }^{1}$ and M E Symonds \\ Early Life Nutrition Research Unit, and Respiratory Biomedical Research Unit, School of Clinical Sciences, Academic \\ Child Health, University Hospital, Nottingham NG7 2UH, UK, ${ }^{1}$ School of Veterinary Medicine and Science, \\ University of Nottingham, Nottingham NG7 2UH, UK, ${ }^{2}$ The MacCaulay Institute, Aberdeen AB15 8QH, UK and \\ ${ }^{3}$ Alberta Institute of Human Nutrition, University of Alberta, Edmonton, Alberta, Canada T6G $\mathrm{OH} 3$ \\ Correspondence should be addressed to M E Symonds; Email: michael.symonds@nottingham.ac.uk
}

\begin{abstract}
The recent discovery of an association between body composition, energy intake and the fat mass and obesity-associated (FTO) gene represents a promising new therapeutic target in obesity prevention. In a well, pre-established large animal model, we investigated the regulation of $F T O$ gene expression under conditions either leading to obesity or increased risk of obesity related disorders: i) a sedentary 'Western' lifestyle and ii) prenatal exposure to nutrient restriction. Pregnant sheep were either fed to fully meet their nutritional requirements throughout gestation or $50 \%$ of this amount from early-to-mid gestation. Following weaning, offspring were either made obese through exposure to a sedentary obesogenic environment or remained lean. A significant positive relationship between placental FTO gene expression and fetal weight was found at $\mathbf{1 1 0}$ days gestation. In both the newborn and adult offspring, the hypothalamus was the major site of $F T O$ gene expression. Hypothalamic FTO gene expression was upregulated by obesity and was further increased by prenatal nutrient restriction. Importantly, we found a strong negative relationship between the hypothalamic FTO gene expression and food intake in lean animals only that may imply FTO as a novel controller of energy intake. In contrast, FTO gene expression in the heart was downregulated in obese offspring born to nutrient restricted mothers. In addition, FTO gene expression was unaffected by obesity or prenatal diet in insulin-dependent tissues, where it changed with age possibly reflecting adaptations in cellular energetic activity. These findings extend information gained from human epidemiology and provide new insights into the regulation of in vivo energy metabolism to prevent obesity.

Reproduction (2010) 139 265-274
\end{abstract}

\section{Introduction}

The global incidence of obesity is currently exhibiting a dramatic increase worldwide in children, adolescents, and adults. Obesity (i.e. body mass index (BMI) $>30 \mathrm{~kg} / \mathrm{m}^{2}$ ) is a well-defined pathological state due to excessive accumulation of lipids in white adipose tissue; however, its main causes remain an area of intense debate (Blakemore \& Froguel 2008, Dina 2008, O'Rahilly \& Farooqi 2008). Very recently, genomewide association studies reproducibly found genetic variants in the fat mass and obesity-associated (FTO) gene to be strongly associated with the risk of obesity (Dina et al. 2007, Price et al. 2008, Tan et al. 2008, Timpson et al. 2008, Villalobos-Comparan et al. 2008) They consistently found that FTO single nucleotide polymorphisms (SNP) between populations, especially for the SNP rs9939609 carriers, are related to substantial rises in BMI, body weight, and/or waist circumference
(Timpson et al. 2008); although others have suggested it may only account for $1 \%$ of the heritability of obesity in humans (Dina 2008).

The main function of the product of the FTO gene is yet to be discovered. This gene is widely expressed in a range of human (Timpson et al. 2008) and animal (Gerken et al. 2007) tissues, with its expression being highest in the brain including the hypothalamic arcuate nucleus, one of the main appetite regulating centers (Gerken et al. 2007). In mice (Gerken et al. 2007) and rats (Fredriksson et al. 2005), hypothalamic Fto mRNA abundance is modulated by nutritional status in a species-dependent manner. In mice, starvation downregulates Fto mRNA transcription (Gerken et al. 2007), whereas in rats the opposite effect is seen (Fredriksson et al. 2005). Although these results contradict each other, they, together with human data, show an association between energy intake and FTO polymorphisms 
(Teng et al. 2002, Wardle et al. 2008, 2009), suggesting that the product of the FTO gene could be involved in energy balance regulation. In addition, the FTO gene is ubiquitously expressed in all peripheral tissues tested to date. This includes some of the key tissues or organs involved in the control of energy metabolism and cardiovascular function (i.e. liver, adipose tissue, skeletal muscle, heart, kidney, and pancreas; Gerken et al. 2007, Stratigopoulos et al. 2008, Wahlen et al. 2008). The extent to which alterations of FTO regulation in these organs can be involved in obesity and obesity-related disorders remain unknown. Interestingly, adipocyte FTO expression is upregulated with human obesity (Zabena et al. 2009) and FTO SNP allelic distribution correlates with some of the common features of obesity and insulin resistance syndrome, i.e. raised plasma leptin, adiponectin, C reactive protein (Do et al. 2008, Fisher et al. 2009). Finally, adipocyte FTO has also been suggested to play a role in the regulation of lipolysis (Do et al. 2008, Shoulders 2008).

The FTO gene could thus have a primary role in the occurrence of obesity. To assess its biological role, tissuespecific gene expression needs to be studied within the context of exposure to obesogenic environments. In conjunction with energy imbalance and genetic predisposition, obesity, or risk of obesity-related disorders, can also originate from the prenatal energetic environment. Indeed, the nutritional status, during critical periods, in which the fetus grows and develops, is an important factor in determining body weight and energy homeostasis (McMillen et al. 2004, 2005, Symonds et al. 2005). The extent to which the FTO gene is developmentally regulated and may be reset by the in utero environment is yet to be determined and was thus the primary aim of the present study. We therefore examined FTO mRNA expression in a range of tissues sampled from mothers and offspring during critical stages of development, i.e. in the i) placenta at mid-gestation, ii) neonate at 7 days of age, and iii) lean and obese adults at 1 year. This analysis was undertaken in tissue samples taken from mothers fed to requirements and those nutrient restricted (NR) from early-to-mid gestation; a period we have previously established to have a pronounced impact on the control of food intake and organ endocrine sensitivity either in the neonate (Whorwood et al. 2001) or in the adult following obesity (Sebert et al. 2009, Sharkey et al. 2009).

\section{Results}

\section{Study 1: placental expression of FTO}

Maternal nutrient restriction during critical periods of gestation can affect placental function and metabolism (Gnanalingham et al. 2007). That said, in Scottish Blackface sheep, we found no significant effects of maternal nutrient restriction from 30 to 65 days gestation on either placental (Control (C): $(n=4): 630 \pm 161 ; \mathrm{NR}$ : $(n=5): 636 \pm 94 \mathrm{~g})$ or fetal body (C: $2.08 \pm 0.12 ; \mathrm{NR}$ : $2.22 \pm 0.20 \mathrm{~kg}$ ) weight at 110 days gestation. Interestingly, FTO mRNA transcription was highly abundant in placental tissue as compared to the other tissues characterized in the present study (Fig. 1). Its expression was, however, unaffected by maternal nutrient intake during early-to-mid gestation (C: $(n=4): 1.0 \pm 0.3$; NR: $(n=5)$ : $1.5 \pm 0.4$-fold change; arbitrary units). Nevertheless, we observed a positive relationship between placental FTO mRNA abundance and fetal weight as determined at 110 days gestation (Fig. 2).

\section{Study 2: influence of obesity and maternal nutrient restriction on FTO gene expression}

Maternal nutrient restriction by $50 \%$ from early-to-mid gestation had no effect on either birth or bodyweight or organ mass up to 7 days of age (Table 1). As expected, post-weaning exposure to an obesogenic environment
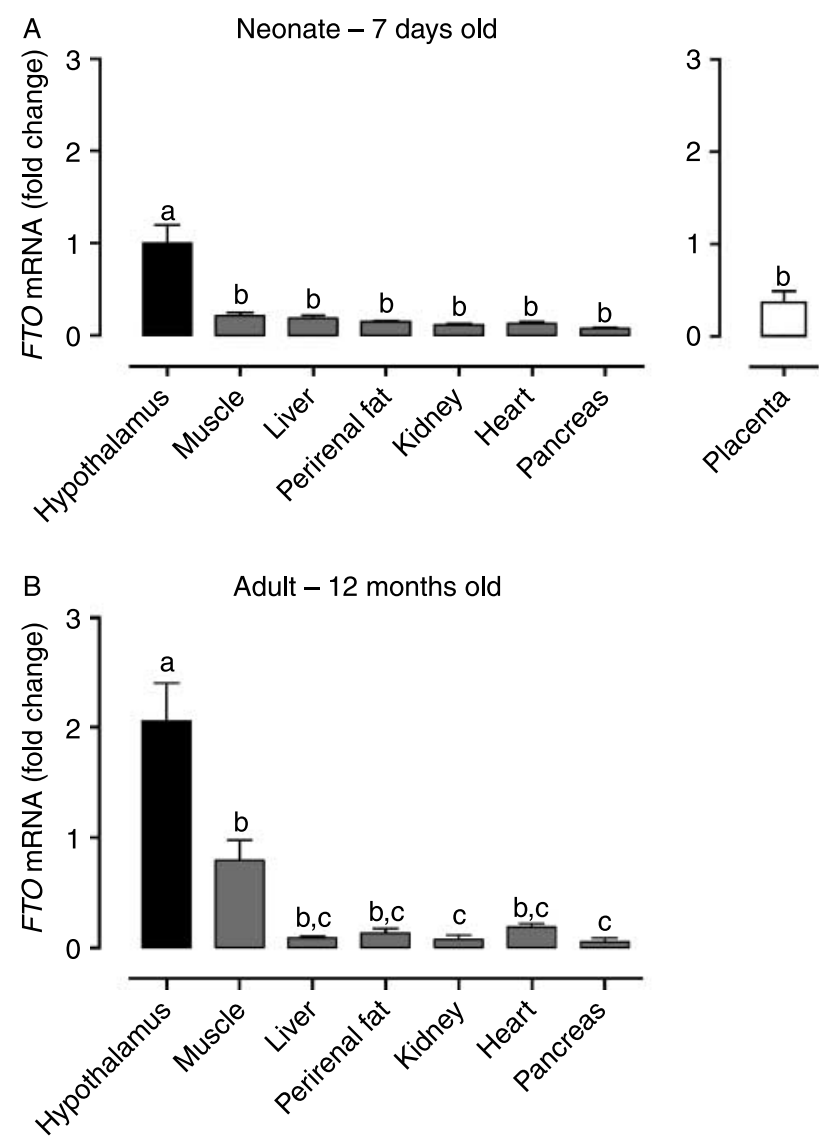

Figure 1 Comparison of FTO gene expression in all major tissue types in offspring born to control fed animals sampled as either $(A)$ neonates (i.e. 7 days of age), together with the 110 day placenta and (B) young adults (i.e. 1 year of age). Values represent means \pm s.E.M.; different superscript within each age group indicates significant differences between tissues (a vs b $P<0.05$; a vs c $P<0.001$ ). 


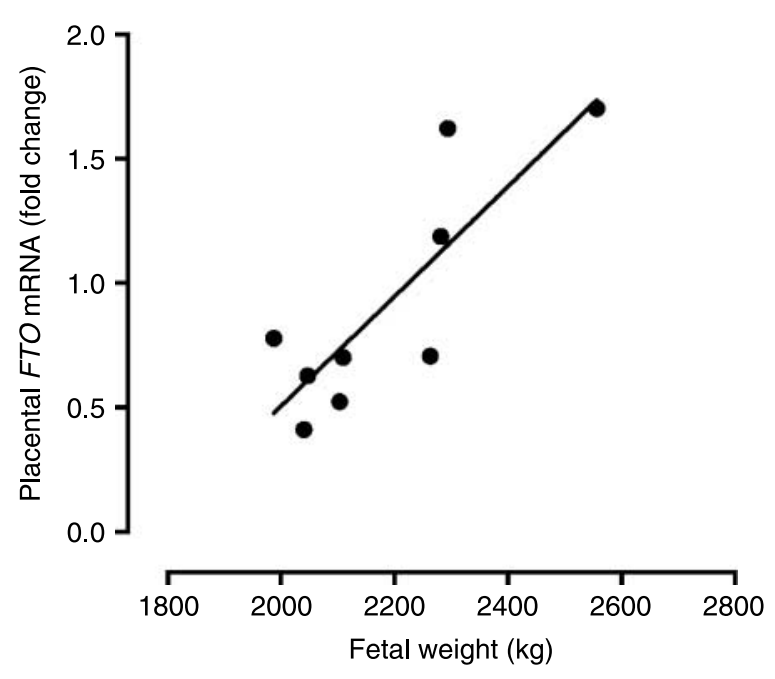

Figure 2 Significant positive relationship $\left(r^{2}=0.7 ; P=0.005\right)$ between fetal body weight at 110 days gestation and placental FTO gene expression.

markedly increased total body weight as well as fat mass at 1 year of age (Table 1). The only organ that did not increase in size in proportion to the rise in total body mass was the heart. The prenatal environment had no influences on body mass and composition following obesity in NR obese (NRO) offspring.

We have previously described in more detail (Williams et al. 2007, Sebert et al. 2009, Sharkey et al. 2009) that maternal nutrient restriction during early-to-mid-gestation influenced the outcomes of juvenile obesity. Critically, concerning the control of food intake, NRO offspring ate substantially less than obese offspring born to control mothers (obese $(\mathrm{O}): 15.9 \pm 0.5 \mathrm{MJ} / 24 \mathrm{~h} ; \quad \mathrm{NRO}: 12.1 \pm 0.8 \mathrm{MJ} / 24 \mathrm{~h}$; $P<0.05)$, an adaptation driven by the hypothalamus through upregulation of the energy sensing pathways (Sebert et al. 2009).

\section{FTO gene expression and distribution}

The FTO gene is a well-conserved gene between animal species (Fredriksson et al. 2005). Sequence data obtained for the FTO amplicon confirmed sequence homology to ovine FTO and to the FTO gene across species including humans (Fig. 3) suggesting comparative functionality. As in humans (Timpson et al. 2008), the ovine FTO gene was expressed in a wide variety of tissues, with maximal abundance in the hypothalamus, followed by skeletal muscle, and placenta. A majority of the other tissues analyzed showed an approximate tenfold lower expression when compared to the hypothalamus (Fig. 1A and B). Importantly, this hypothalamic predominance was observed both at birth and in adulthood. In addition, the lowest expression of FTO mRNA was measured in the kidney and pancreas.

\section{Tissue-specific FTO gene expression}

Hypothalamus. Prenatal nutrient restriction was not found to alter FTO gene expression in the newborn. However, FTO mRNA abundance doubled between birth and 1 year of age (Fig. 4A). FTO gene expression in the hypothalamus was amplified with obesity $(P<0.05)$ and, importantly, prenatal exposure to maternal nutrient restriction in early pregnancy resulted in a further upregulation in FTO mRNA transcription induced by obesity $(P<0.01$ against $\mathrm{O}$ animals). Finally, we observed a significant negative correlation between food intake and FTO gene expression in lean animals at one year of age (Fig. 4B), a relationship lost with obesity.

Heart. No immediate effect of the prenatal diet on cardiac FTO gene expression was measured in the newborn. Nonetheless, in the 1 -year-old NR offspring following obesity, cardiac FTO mRNA abundance was significantly downregulated compared to obese offspring born to control mothers (Fig. 5).

Table 1 Morphometric measurements in (A) newborn and (B) adult (1-year-old) offspring. Values are means with their S.E.M. from offspring born to control (C) or nutrient restricted (NR) mothers in neonatal and adult offspring that remained lean (L) or became obese $(\mathrm{O})$.

\begin{tabular}{|c|c|c|c|c|c|c|c|c|c|c|c|}
\hline & \multicolumn{2}{|c|}{ Body weight (kg) } & \multicolumn{9}{|c|}{ Individual tissues/organs } \\
\hline & Birth & 7 days & & PAT (g) & Fat $(\mathrm{g} / \mathrm{kg})$ & Kidney ( & Live & $r(g)$ & Heart (g) & Pancreas (g) & Brain $(g)$ \\
\hline \multicolumn{12}{|l|}{ (A) } \\
\hline $\mathrm{C}(n=7)$ & $3.3 \pm 0.2$ & $4.4 \pm 0.3$ & & $43 \pm 7$ & $8.9 \pm 0.8$ & $30 \pm 1$ & 121 & \pm 5 & $33 \pm 2$ & $3.6 \pm 0.4$ & $53 \pm 2$ \\
\hline \multirow[t]{4}{*}{$\mathrm{NR}(n=12)$} & $3.2 \pm 0.2$ & $4.6 \pm 0.3$ & & $49 \pm 5$ & $9.2 \pm 1$ & $27 \pm 1$ & 122 & \pm 9 & $36 \pm 2$ & $4.9 \pm 0.4$ & $53 \pm 1$ \\
\hline & \multirow[b]{3}{*}{ Weight (kg) } & \multicolumn{10}{|c|}{ Individual tissues/organs } \\
\hline & & \multicolumn{2}{|l|}{ PAT } & \multicolumn{2}{|c|}{ Kidneys } & \multicolumn{2}{|c|}{ Liver } & \multicolumn{2}{|c|}{ Heart } & \multicolumn{2}{|c|}{ Pancreas } \\
\hline & & (g) & $(\mathrm{g} / \mathrm{kg})$ & (g) & $(g / k g)$ & (g) & (g/kg) & (g) & (g/kg) & (g) & $(\mathrm{g} / \mathrm{kg})$ \\
\hline \multicolumn{12}{|l|}{ (B) } \\
\hline $\mathrm{L}(n=7)$ & $58 \pm 4$ & $500 \pm 93$ & $10 \pm 2$ & $117 \pm 9$ & $2.0 \pm 0.1$ & $602 \pm 36$ & $10 \pm 0.4$ & $238 \pm 10$ & $4.1 \pm 0.1$ & $53 \pm 3.5$ & $0.9 \pm 0.1$ \\
\hline $\mathrm{O}(n=8)$ & $91 \pm 2^{\ddagger}$ & $2690 \pm 214^{\ddagger}$ & $30 \pm 3^{\ddagger}$ & $155 \pm 7^{+}$ & $1.7 \pm 0.04$ & $897 \pm 59^{\ddagger}$ & $10 \pm 0.3$ & $309 \pm 12 *$ & $3.4 \pm 0.1^{\neq}$ & $60 \pm 6.3$ & $0.7 \pm 0.1^{+}$ \\
\hline $\mathrm{NRO}(n=8)$ & $89 \pm 2$ & $2820 \pm 212$ & $30 \pm 2$ & $168 \pm 7$ & $1.9 \pm 0.1$ & $881 \pm 50$ & $10 \pm 0.6$ & $290 \pm 8$ & $3.3 \pm 0.2$ & $61 \pm 4.5$ & $0.7 \pm 0.1$ \\
\hline
\end{tabular}

Significant differences between $\mathrm{L}$ and $\mathrm{O}$ groups indicated by: ${ }^{*} P<0.05 ;{ }^{\dagger} P<0.01 ;{ }^{\ddagger} P<0.001$. $\mathrm{PAT}$, perirenal adipose tissue. 


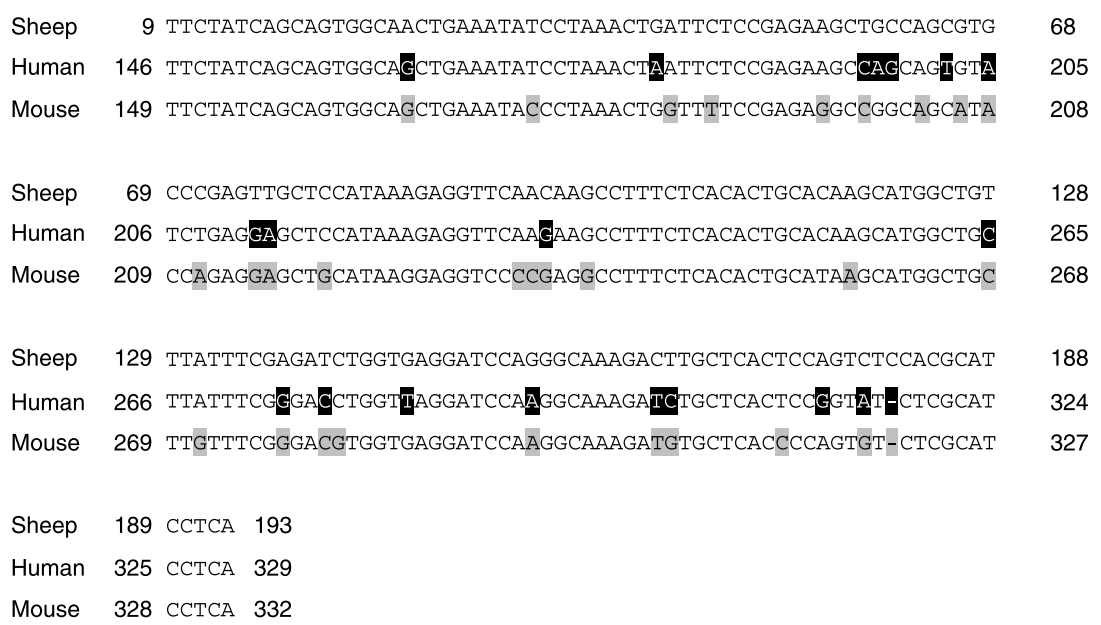

Pancreas. Pancreatic FTO gene expression was decreased with age $(P<0.05)$. Interestingly, we measured a further reduction of its expression following obesity but no specific effect of the prenatal diet was seen (Table 2).

Kidney. Similar to the pancreas, renal FTO gene expression was unaffected by the prenatal diet. However, obese animals exhibited a significant upregulation of FTO mRNA abundance (Table 2).

Adipose tissues. FTO mRNA abundance was similar between fat depots at 1 year of age (e.g. in lean $(n=7)-$ perirenal: $1.0 \pm 0.12$; pericardial: $1.33 \pm 0.35$-fold change). Perirenal adipose tissue, the most abundant fat depot in our model, expressed more FTO mRNA at 7 days compared to 1 year of age $(P<0.05)$. Obesity tended $(P=0.08)$ to increase adipose tissue FTO mRNA abundance an adaptation that was independent of the maternal nutritional environment (lean $(\mathrm{L})=0.7 \pm 0.1$; $\mathrm{O}=1.1 \pm 0.2 ; \mathrm{NRO}=1.0 \pm 0.2$ ).

Liver and skeletal muscle. There was no effect of prenatal diet and the age-related changes between 7 days and 1 year of age in FTO mRNA abundance (i.e. decrease in liver and an increase in skeletal muscle) were unaffected neither by obesity nor maternal nutrition (Table 2 ) in both tissue types.

\section{Discussion}

Within the past year exciting new evidence from genome-wide association studies reproducibly highlighted the FTO SNP allelic distribution as a predictive factor for obesity in various human populations (Dina et al. 2007, Al-Attar et al. 2008, Freathy et al. 2008, Hotta et al. 2008, Hubacek et al. 2008, Timpson et al. 2008, Willers et al. 2008, Gonzalez-Sanchez et al. 2009). The mechanisms underlying the physiological relationship between FTO allelic variations and alterations of body weight homeostasis are yet to be elucidated. Tissue-specific genetic regulation of FTO transcription together with obesity development represents a first step to assess its biological functions. Our study thus explored, for the first time, the regulation of the FTO gene transcription in experimental environments known to promote obesity-related metabolic
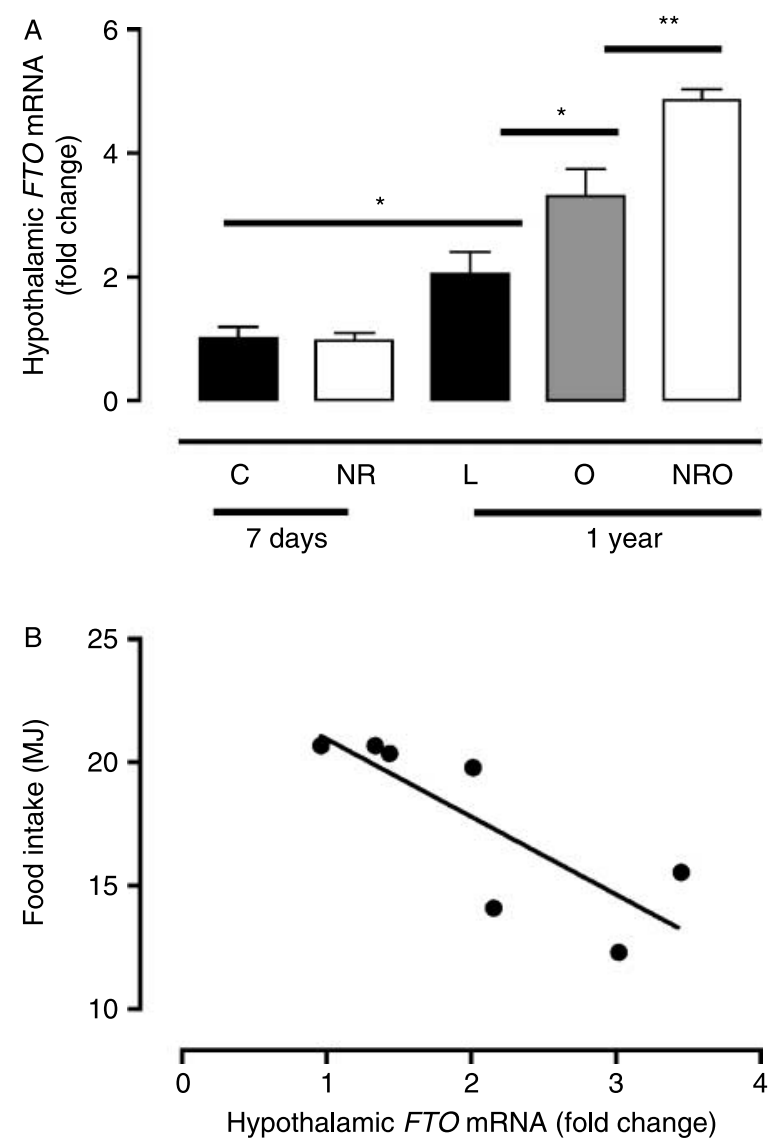

Figure 4 FTO gene expression in (A) the hypothalamus in the neonatal (i.e. 7 days of age) and adult sheep that were born to either control (C) fed mothers or those nutrient restricted between 30 and 80 days gestation $(\mathrm{NR})$ and then remained lean $(\mathrm{L})$ or became obese $(\mathrm{O})$ and (B) significant negative relationship $\left(r^{2}=0.42 ; P=0.001\right)$ with food intake in adult lean animals. Values represent means \pm S.E.M.; ${ }^{*} P<0.05$, $* * P<0.01$. 


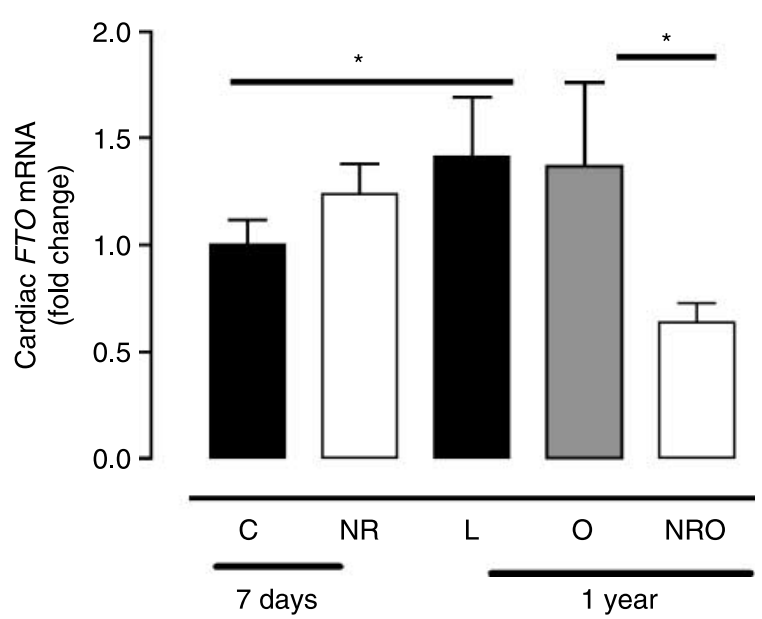

Figure 5 FTO gene expression in the heart in the neonatal and adult sheep that were born to either control (C) fed mothers or those nutrient restricted between 30 and 80 days gestation (NR) and then remained lean $(\mathrm{L})$ or became obese $(\mathrm{O})$. Values represent means \pm S.E.M., $* P<0.05$.

disorders. We have thus demonstrated obesity-related alterations of FTO together with the novel finding that FTO gene expression is developmentally regulated in the hypothalamus and in the heart, a response dependent on the prenatal nutritional environment.

\section{Obesity-related alterations}

Overweight sheep offers an interesting alternative model to study the origins and consequences of human obesity (Sharkey et al. 2009) although it is recognized that the sheep is a ruminant and thus has a very different diet and digestive system to humans. Notwithstanding this point this model of environmental induction of obesity, excessive body fat deposition resulted in similar physiological and metabolic complications to those seen in human obesity including glucose intolerance, hyperinsulinemia, hyperleptinemia, and leptin resistance together with raised blood pressure (Williams et al. 2007, Sebert et al. 2009, Sharkey et al. 2009). In our model, one of the main obesity-related changes in FTO gene expression was an upregulation in the entire hypothalamus. In mice, FTO is predominantly expressed in the arcuate nucleus of the hypothalamus (Gerken et al. 2007), a key neuronal centre for food intake control (Masuzaki et al. 2001) and therefore suggest a role for FTO in the control of food intake. It thus raises the question as to whether the alteration of hypothalamic FTO gene expression that we found partly characterized the dysregulation of the control of food intake related to obesity (Sebert et al. 2009). Intriguingly, we found hypothalamic FTO mRNA abundance in lean animals to be negatively related to daily energy intake. This relationship was lost with obesity but, the further elevation of FTO expression in the offspring born to NR mothers was associated with a significant reduction of food intake. In addition, together with findings from both human and animal studies, our study further supports a role for FTO in the control of food intake that appears to be reset following obesity. In rodents, hypothalamic FTO gene expression is associated with energy intake (Fredriksson et al. 2005, Gerken et al. 2007), while in humans, allelic distributions of FTO SNPs are similarly related to alterations of energy intake in childhood (Timpson et al. 2008, Wardle et al. 2009). It thus appears possible that the FTO SNP rs9939609 promotes substantial perturbations in energy balance that ultimately leads to obesity.

Results from human studies further indicate that FTO gene expression in adipocytes can be upregulated in obesity (Kloting et al. 2008, Zabena et al. 2009), an adaptation dependent on duration and severity. In our ovine model, we found a trend for a similar response in perirenal adipose tissue, suggesting that with an extended period of obesity the same adaptation would occur. We also observed for the first time that adolescent-onset obesity was associated with local alterations of FTO gene expression in the kidney and pancreas. The extent to which such changes in FTO gene regulation are a cause or consequence of obesity and thus has a role in the etiology of the classical perturbations observed during the metabolic syndrome remains to be established.

Table 2 Fat mass and obesity-associated (FTO) gene expression in insulin and noninsulin-dependent tissues. Values are means with their S.E.M. from offspring born to control (C) or nutrient restricted (NR) mothers in neonatal and adult offspring that remained lean (L) or became obese (O).

\begin{tabular}{|c|c|c|c|c|c|}
\hline \multirow[b]{2}{*}{ Tissues/organs } & \multicolumn{2}{|c|}{7 days old } & \multicolumn{3}{|c|}{ 1-year-old } \\
\hline & $\mathrm{C}(n=7)$ & $\mathrm{NR}(n=7)$ & $\mathrm{L}(n=7)$ & $\mathrm{O}(n=7)$ & $\operatorname{NRO}(n=8)$ \\
\hline \multicolumn{6}{|c|}{ Insulin-dependent tissues } \\
\hline Liver & $1.0 \pm 0.2$ & $0.9 \pm 0.1$ & $0.5 \pm 0.1^{*}$ & $0.5 \pm 0.1$ & $0.5 \pm 0.1$ \\
\hline PAT & $1.0 \pm 0.1$ & $1.2 \pm 0.1$ & $0.7 \pm 0.1 *$ & $1.1 \pm 0.2$ & $1.0 \pm 0.2$ \\
\hline SM & $1.0 \pm 0.2$ & $1.0 \pm 0.1$ & $3.7 \pm 0.9^{*}$ & $4.0 \pm 0.4$ & $3.6 \pm 0.6$ \\
\hline \multicolumn{6}{|c|}{ Noninsulin-dependent tissues } \\
\hline Kidney & $1.0 \pm 0.1$ & $0.8 \pm 0.1$ & $0.7 \pm 0.3$ & $1.2 \pm 0.2^{+}$ & $1.0 \pm 0.2$ \\
\hline Pancreas & $1.0 \pm 0.2$ & $1.2 \pm 0.2$ & $0.7 \pm 0.5$ & $0.2 \pm 0.1^{+}$ & $1.3 \pm 0.9$ \\
\hline
\end{tabular}

Significant differences with age between control animals (i.e. C; 7 days versus $L ; 1$ year of age) indicated by $* ; * P<0.05$. Significant differences between $\mathrm{L}$ and $\mathrm{O}$ groups at 1 year of age indicated by $+{ }^{\dagger}{ }^{\dagger} P<0.05$. PAT, perirenal adipose tissue; $S M$, skeletal muscle. 


\section{FTO as a critical factor for the fetal programming of obesity-related disorders?}

The actual risk for obesity and cardiovascular diseases are now established to be directly influenced by the fetal nutritional environment (McMillen \& Robinson 2005, Hanson \& Gluckman 2008). Epigenetic alterations promoted by the early nutritional environment modulate, in part, genotype plasticity to enable the developing fetus to adapt to changes in nutrient supply (McMillen \& Robinson 2005). FTO gene expression is upregulated in the hypothalamus following a combination of in utero exposure to nutrient restriction followed by juvenile obesity. In the present study, we also found FTO mRNA to be highly expressed in the placenta and to be positively related to fetal weight. This strong relationship suggests that FTO is one factor involved in regulating fetal energy supply a proposal that is supported by the observation in newborn humans in which, the rs9939609SNP in FTO is positively associated with specific metabolic parameters including fat mass and visfatin concentration (Lopez-Bermejo et al. 2008).

We did not, however, find any alterations in FTO mRNA abundance in any of the neonatal tissues examined. Nonetheless, the developmental origins of adult health and diseases remain a complex physiological process. Cell-specific adaptations to changes in the fetal nutritional environment appear to be dependent not only on the in utero environment but also to a potential mismatch between the pre- and post-natal nutritional environments (Hanson \& Gluckman 2008, Vickers et al. 2008). Our results, therefore, suggest that adolescent onset of obesity is necessary to induce the phenotypic responses programmed by maternal nutrient restriction. However, future work will need to incorporate lean offspring born to NR mothers in order to fully confirm our hypothesis. Nevertheless, previous works from our group have already seen no differences in the control of food intake or metabolism in these offspring when they remain lean (Gopalakrishnan et al. 2005, Hyatt et al. 2007). Two of our main findings are that FTO gene expression in NR offspring is reset in the hypothalamus and heart following adolescent-onset obesity. The period of early-to-mid gestation in the sheep can be compared to the first trimester of human pregnancy and represents a period of maximal placental growth that coincides with critical periods of heart morphogenesis and neuronal network remodeling, including hypothalamic networks. Maternal nutrient restriction was therefore specifically chosen in order to establish the long-term adaptations upon the functions of these organs following obesity. The main characteristics of our particular model is a reduction of food intake following obesity (Sebert et al. 2009), without substantial weight loss, and intra-cardiac accumulation of triglycerides (Chan et al. 2009) in conjunction with marked adipose tissue-specific stress and inflammation responses (Sharkey et al. 2009). Taken together, these adaptations suggest an amplified response to obesity in offspring born to NR mothers. Interestingly, FTO was one of the few genetic factors, co-expressed together with modulators of energy sensing e.g. PRKA (AMPK), ACACA (ACC-alpha), and PPARGC1A (PGC-1 alpha), for which hypothalamic gene expression in the adult is promoted by maternal nutrient restriction (Sebert et al. 2009). We thus suggest that during this critical developmental window, early maternal nutrient restriction induced long-term adaptation towards hypothalamic and cardiac energy sensing. These findings could now enable us to gain a better understanding of the developmental origins of obesity and metabolic diseases. We therefore raise the question as to whether the developmentally-induced modulations of FTO expression are related to a consistent resetting of energy sensing. Using bioinformatic sequence homology analysis, the FTO gene has been shown to encode a 2-oxoglutarate-dependent DNA demethylase (Gerken et al. 2007, Sanchez-Pulido \& Andrade-Navarro 2007). This indicates a novel molecular link between energy generated via the Krebs cycle through modulation of intra-cytoplasmic concentrations of 2-oxoglutarate concentration, and gene transcription via DNA demethylation. It could therefore be very likely that cell metabolism may regulate FTO gene expression and this clearly requires further investigation. Tissuespecific biological functions of the FTO-related peptide remain to be fully established. However, a recently developed FTO-deficient mouse (Fischer et al. 2009) provides new insights into the biological systems regulated by FTO. Systemic depletion of the FTO gene resulted in major growth impairment of white, but not brown, adipose tissue leading to lipodystrophy and resistance against obesity. These mice were also hyperphagic and exhibited substantial alterations in energy expenditure leading to raised heat production. The extent to which similar roles are present in large mammals remains to be established but we clearly observed that the early nutritional environment can have a modulating role.

An improved understanding of the primary mechanisms regulating body weight homeostasis and energy balance is critical to current public health concerns with respect to obesity. In this regard, we have found that regulation of the FTO gene undergoes profound developmental adaptations that are dependent on maternal nutritional status, age, and fat mass. It is highly expressed in the hypothalamus and represents a new molecule involved in the control of food intake. Furthermore, FTO gene expression is modified by obesity both in the hypothalamus and the heart following exposure to prenatal NR coincident with early organogenesis. As to whether the specific alterations of FTO gene expressions we observed, following NR, either contributes directly or are a compensatory factor towards obesity development requires further investigation. In addition to fetal programming of FTO gene expression, 
we found obesity-dependent effects on FTO gene expression in the hypothalamus, adipose tissue, kidney, and pancreas that could represent an important adaptation in obesity development and obesity-related diseases such as hypertension and type II diabetes. There is a clear need for further research efforts to be prioritized in this area. Taken together, our unique findings lends further support to previous small animal studies (Fredriksson et al. 2005, Gerken et al. 2007, Fischer et al. 2009) for the FTO gene to be classified as a novel controller of food intake and as a cellular energy sensor that is developmentally and nutritionally regulated. Importantly, we confirm some strong links between FTO and obesity, in a large animal model, that may promote the discovery of new pathways for targeting therapeutic strategies designed to prevent obesity and its associated metabolic complications and social and financial implications.

\section{Materials and Methods}

\section{Animals, diets and experimental design}

All procedures were performed in accordance with the UK Animals (Scientific Procedures) Act (1986) and approved by the local ethics committee of the University of Nottingham and
Aberdeen. The present paper utilized tissue samples obtained from two independent studies previously performed which were designed to analyze the nutritional regulation of placental development and the fetal programming of obesity and related disorders as summarized in Fig. 6. These two independent studies thus provide an excellent opportunity to answer our hypothesis but cannot be interpreted as a single study.

Study 1: influence of nutrient restriction during the period of maximal placenta growth on placental FTO gene

Nine singleton-bearing Scottish Blackface sheep were either fed a control diet $(n=4)$ or a $50 \%$ of this amount i.e. NR $(n=5)$ during the period of maximal placenta growth in sheep i.e. between 30 and 65 days of gestation, as previously described (Brennan et al. 2005). At 110 days of gestation, all mothers were euthanized, the fetus weighed, and placentomes randomly sampled for molecular analysis.

Study 2: influence of maternal nutrient restriction followed by adolescent-onset obesity on FTO gene expression in resultant offspring

FTO gene expression was assessed in a range of tissue samples collected from animals previously used to study the early nutritional programming of food-intake regulation (Sebert et al. 2009). Briefly, at day 30 of gestation, 25 twin-bearing Welsh

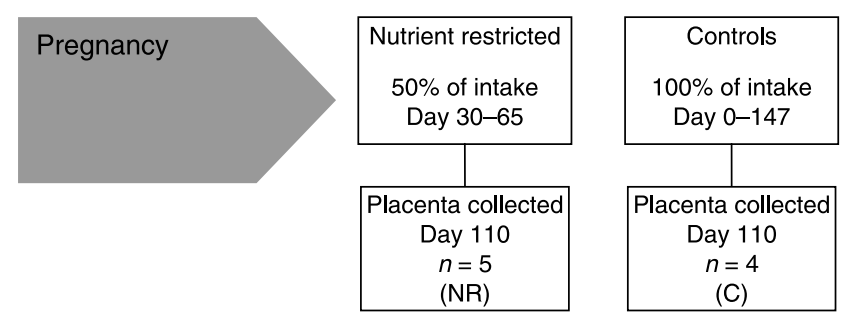

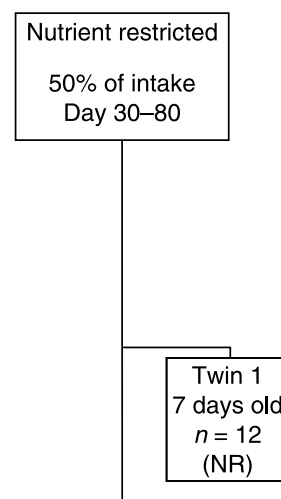

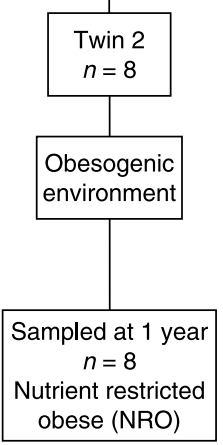

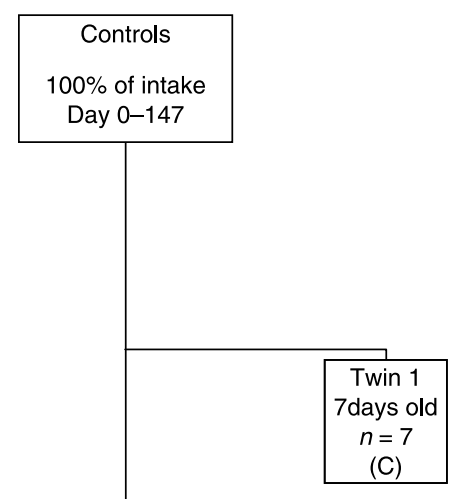

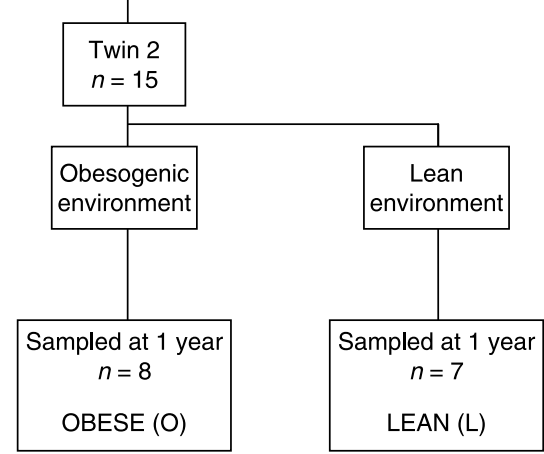

NR vs. C
Obese vs. NRO

Figure 6 Summary of the experimental protocol from conception through to adulthood. See Materials and Methods section for further details. 
Mountain sheep were randomly allocated into two groups to receive either a control (7 MJ/day: C: $n=15)$ or NR (50\% of C, $n=10$ ) diet until day 80 of gestation (Fig. 6). Thereafter, all sheep were fed $100 \%$ of their calculated metabolisable energy requirements up to term (12-13 MJ/day near term; Agricultural and Food Research Council 1993). All offspring were delivered spontaneously at term $(\sim 147$ days). The female to male ratio was $(1: 1)$ in the control and $(2: 1)$ in the NR group. Seven control offspring and $12 \mathrm{NR}$ offspring were tissue sampled at 7 days of age. For ethical considerations, in order to reduce the number of mothers entered into the study, eight of the newborn control twins (twin 1) were allocated to a separate independent study. The remaining offspring (C: $n=15 ; \mathrm{NR}: n=8)$ were reared by their mothers until weaning ( $\sim 10$ weeks of age). During lactation, all mothers were fed a diet of hay ad libitum, together with a fixed amount of concentrate pellets, sufficient to fully meet their own metabolizable requirements, as well as those required to maintain lactation. From weaning to 12 months of age, the $\mathrm{O}(n=8)$ and NR $(n=8)$ offspring were exposed to an 'obesogenic' environment: i.e. group housed in a barn at a stocking rate of 17 animals per $50 \mathrm{~m}^{2}$ with ad libitum access to hay and concentrate pellets, as previously described (Sebert et al. 2009). The remaining control offspring $(n=7)$ were reared in a nonobesogenic standard 'free-living' environment: i.e. put out in the pasture at a stocking rate of 17 animals per $3000 \mathrm{~m}^{2}$ with free-grazing allowance and a fixed amount of concentrate pellets (400 g/day). Neonatal offspring sampled at 7 days of age were thus grouped according to the maternal nutritional environment: i.e. control or NR. The remaining post weaning 'free-living' offspring were defined as $\mathrm{L}(n=7)$. Offspring raised in the obesogenic environment were redefined as $\mathrm{O}(n=8)$ or NRO $(n=8)$. Just prior to dissection, at 12 months of age, adult offspring were individually penned and their daily energy intake recorded (i.e. food offered minus food refusal over $24 \mathrm{~h}$ ) in order to assess some aspects of food intake regulation (Sebert et al. 2009).

\section{Post-mortem analysis}

\section{Study 1}

At dissection (110 day gestation), individual placentomes were dissected and weighed in order to calculate total placental mass for each fetus. Fetal body weight was also recorded. Representative A type placentomes (that constitute $\sim 80 \%$ of all placentomes at this stage of gestation) were randomly sampled, snap frozen in liquid nitrogen and stored at $-80^{\circ} \mathrm{C}$. Approximately $100 \mathrm{mg}$ of maternal caruncular placentome were dissected for RNA extraction.

\section{Study 2}

All offspring were tissue sampled in the morning between 0900 and $1100 \mathrm{~h}$. The 1-year-old offspring were euthanized as previously described after an overnight fast (Williams et al. 2007). Seven day old offspring could not be subjected to a similar period of food withdrawal as this would have meant prolonged physical separation from their mothers and, as such, would have been unethical. Following euthanasia, the whole brain was immediately recovered and the entire hypothalamus dissected, snap frozen in liquid nitrogen and stored at $-80{ }^{\circ} \mathrm{C}$ as previously described (Sebert et al. 2009). In addition, the perirenal adipose tissue depot, that is the most abundant depot in young sheep (Alexander \& Bell 1975), heart, kidney, liver, pancreas, and skeletal muscle (Longissimus dorsi) were rapidly sampled, snap frozen in liquid nitrogen and immediately stored at $-80{ }^{\circ} \mathrm{C}$ until molecular analyses.

\section{Determination of FTO expression and mRNA abundance}

Total RNA was extracted from all tissues using Qiazol lysis reagent and RNeasy extraction kit (Qiagen Ltd) which included a DNAse I digestion (RNase-Free DNase Set, Qiagen Ltd). In the case of adipose tissue the lipid was first discarded (Sebert et al. 2005). One microgram of total RNA was then reverse transcribed into cDNA (Superscript II RT, Invitrogen Ltd). FTO gene expression was determined using the entire hypothalamus as has previously been used to study the regulation of food intake in rats (Teske et al. 2006, Sahu 2008), mice (Sellayah et al. 2008), and sheep (Warnes et al. 1998, Sebert et al. 2009). It is recognized that the hypothalamus is not a homogeneous entity but includes many nuclei that may exhibit differential regulation of FTO gene expression (Gerken et al. 2007). The advantage of using the entire hypothalamus is that it enabled us to obtain quantitative information with regard to the effect of age, maternal diet, obesity, and to compare FTO gene expression between tissues.

The FTO primers utilized were; forward: 5'-ACA CAT GGC TTC CCT ACC TG-3', reverse: 5'-GAG GAT GCG AGA GAC TGG AG-3' were designed from the published ovine FTO sequence (gene bank accession number: EU972419). The PCR product was gel extracted (QIAquick Gel Extraction Kit, Qiagen Ltd) and sequenced (Fig. 6) in order to confirm amplicon specificity and to generate a standard curve (tenfold serial dilutions) for real-time PCR analysis.

Gene expression was determined by a real-time PCR thermocycler (Quantica, Techne Incorporated, Barloword Scientific Ltd, Stone, UK) using the Quantitect SYBR greenbased PCR kit (Qiagen Ltd; Mostyn et al. 2006). 18S rRNA; (forward: 5'-GAT GCG GCG GCG TTA TTC C-3', reverse: $5^{\prime}$-CTC CTG GTG GTG CCC TTC C-3') and Acidic Ribosomal Protein P0 (RPLO) (forward: 5'-AG CAA GTG GGA AGG TGT AAT-3', reverse: CCC ATT CTA TCA TCA ACG GGT A-3') were used as housekeeping genes and results calculated using the $2^{-\Delta C_{t}}$ method (Livak \& Schmittgen 2001). We also assessed the suitability of a number of other house keeping genes including cyclophilin although only RPLO was shown not to be influenced by the in vivo experimental conditions. There was no difference in any of the results obtained when using either $18 \mathrm{~S}$ or RPLO therefore we have only presented results when using 18S. To enable inter-tissue comparisons, the mRNA abundance measured in the 7-day-old hypothalami was chosen as a reference to enable a direct comparison between tissues; this was also the case for the 1-year-old hypothalamus samples. However, to analyze intra-tissue-specific modifications, the mean mRNA abundance of values obtained in the control 
group at 7 days of age for the related tissue was used and therefore, acted as an internal reference for each separate tissue being examined.

\section{Statistical analyses}

Statistical analyses were performed using SPSS v14.0 for Windows (SPSS Inc., Chicago, IL, USA). To assess the data for normality, we performed a Kolmogorov-Smirnov test. Data were all found to be normally distributed and therefore analyzed using parametric tests as follow: Study 1: unpaired Student's $t$-tests were used to compare FTO expression between groups. Study 2: 1) tissue comparisons in the 7-day-old and separately in the 1-year-old offspring were made by one-way ANOVA with Bonferroni post-hoc tests. 2) In order to assess the effects of age (i.e. C (7-day-old) versus L (1-year-old)) paired Student's t-test (comparison of heterozygote twins) were used, 3) both the effect of maternal nutrient restriction (i.e. 7-day-old $\mathrm{C}$ versus $\mathrm{NR}$ and 1 -year-old $\mathrm{O}$ versus $N R O$ animals) and of postnatal obesity ( $L$ versus $O$ ) we used an unpaired Student's $t$-test. Data are presented as means \pm s.E.M., with a $P$ value $<0.05$ indicating statistically significant differences between groups.

\section{Declaration of interest}

The authors declare that there is no conflict of interest that could be perceived as prejudicing the impartiality of the research reported.

\section{Funding}

This work was supported by the European Union Sixth Framework Program for Research and Technical Development of the European Community - The Early Nutrition Programming Project (FOOD-CT-2005-007036), the Nutricia Research Foundation (2009-35), the British Heart Foundation, the Medical Research Council, and the Universities of Nottingham and Alberta.

\section{References}

Agricultural and Food Research Council 1993 Technical Committee on Responses to Nutrients. Report No. 9. In Technical Committee on Responses to Nutrients. Report No. 9, pp 812-815. Wallingford, UK: $\mathrm{CAB}$ International.

Al-Attar SA, Pollex RL, Ban MR, Young TK, Bjerregaard P, Anand SS, Yusuf S, Zinman B, Harris SB, Hanley AJ et al. 2008 Association between the FTO rs9939609 polymorphism and the metabolic syndrome in a non-Caucasian multi-ethnic sample. Cardiovascular Diabetology 75.

Alexander G \& Bell AW 1975 Quantity and calculated oxygen consumption during summit metabolism of brown adipose tissue in newborn lambs. Biology of the Neonate 26 214-220.

Blakemore AI \& Froguel P 2008 Is obesity our genetic legacy? Journal of Clinical Endocrinology and Metabolism 93 S51-S56.

Brennan KA, Gopalakrishnan GS, Kurlak L, Rhind SM, Kyle CE, Brooks AN, Rae MT, Olson DM, Stephenson T \& Symonds ME 2005 Impact of maternal undernutrition and fetal number on glucocorticoid, growth hormone and insulin-like growth factor receptor mRNA abundance in the ovine fetal kidney. Reproduction 129 151-159.
Chan LL, Sebert SP, Hyatt MA, Stephenson T, Budge H, Symonds ME \& Gardner DS 2009 Effect of maternal nutrient restriction from early to mid gestation on cardiac function and metabolism after adolescent-onset obesity. American Journal of Physiology. Regulatory, Integrative and Comparative Physiology 296 R1455-R1463.

Dina C 2008 New insights into the genetics of body weight. Current Opinion in Clinical Nutrition and Metabolic Care 11 378-384.

Dina C, Meyre D, Gallina S, Durand E, Korner A, Jacobson P, Carlsson LM, Kiess W, Vatin V, Lecoeur C et al. 2007 Variation in FTO contributes to childhood obesity and severe adult obesity. Nature Genetics 39 724-726.

Do R, Bailey SD, Desbiens K, Belisle A, Montpetit A, Bouchard C, Perusse L, Vohl MC \& Engert JC 2008 Genetic variants of FTO influence adiposity, insulin sensitivity, leptin levels and resting metabolic rate in the Quebec family study. Diabetes 57 1147-1150.

Fischer J, Koch L, Emmerling C, Vierkotten J, Peters T, Bruning JC \& Ruther U 2009 Inactivation of the Fto gene protects from obesity. Nature 458 894-898.

Fisher E, Schulze MB, Stefan N, Haring HU, Doring F, Joost HG, Al-Hasani H, Boeing H \& Pischon T 2009 Association of the FTO rs9939609 single nucleotide polymorphism with C-reactive protein levels. Obesity $\mathbf{1 7}$ 330-334.

Freathy RM, Timpson NJ, Lawlor DA, Pouta A, Ben-Shlomo Y, Ruokonen A, Ebrahim S, Shields B, Zeggini E, Weedon MN et al. 2008 Common variation in the FTO gene alters diabetes-related metabolic traits to the extent expected given its effect on BMI. Diabetes 57 1419-1426.

Fredriksson JM, Nikami H \& Nedergaard J 2005 Cold-induced expression of the VEGF gene in brown adipose tissue is independent of thermogenic oxygen consumption. FEBS Letters $\mathbf{5 7 9}$ 5680-5684.

Gerken T, Girard CA, Tung YC, Webby CJ, Saudek V, Hewitson KS, Yeo GS, McDonough MA, Cunliffe S, McNeill LA et al. 2007 The obesityassociated FTO gene encodes a 2-oxoglutarate-dependent nucleic acid demethylase. Science 318 1469-1472.

Gnanalingham MG, Williams P, Wilson V, Bispham J, Hyatt MA, Pellicano A, Budge H, Stephenson T \& Symonds ME 2007 Nutritional manipulation between early to mid-gestation: effects on uncoupling protein-2, glucocorticoid sensitivity, IGF-I receptor and cell proliferation but not apoptosis in the ovine placenta. Reproduction $\mathbf{1 3 4}$ 615-623.

Gonzalez-Sanchez JL, Zabena C, Martinez-Larrad MT, MartinezCalatrava MJ, Perez-Barba M \& Serrano-Rios M 2009 Variant rs9939609 in the FTO gene is associated with obesity in an adult population from Spain. Clinical Endocrinology 70 390-393.

Gopalakrishnan GS, Gardner DS, Dandrea J, Langley-Evans SC, Pearce S, Kurlak LO, Walker RM, Seetho IW, Keisler DH, Ramsay MM et al. 2005 Influence of maternal pre-pregnancy body composition and diet during early-mid pregnancy on cardiovascular function and nephron number in juvenile sheep. British Journal of Nutrition 94 938-947.

Hanson MA \& Gluckman PD 2008 Developmental origins of health and disease: new insights. Basic Clinical Pharmacology \& Toxicology 102 90-93.

Hotta K, Nakata Y, Matsuo T, Kamohara S, Kotani K, Komatsu R, Itoh N, Mineo I, Wada J, Masuzaki H et al. 2008 Variations in the FTO gene are associated with severe obesity in the Japanese. Journal of Human Genetics 53 546-553.

Hubacek JA, Bohuslavova R, Kuthanova L, Kubinova R, Peasey A, Pikhart H, Marmot MG \& Bobak M 2008 The FTO gene and obesity in a large eastern European population sample: the HAPIEE study. Obesity 16 2764-2766.

Hyatt MA, Gopalakrishnan GS, Bispham J, Gentili S, McMillen IC, Rhind SM, Rae MT, Kyle CE, Brooks AN, Jones C et al. 2007 Maternal nutrient restriction in early pregnancy programs hepatic mRNA expression of growth-related genes and liver size in adult male sheep. Journal of Endocrinology 192 87-97.

Kloting N, Schleinitz D, Ruschke K, Berndt J, Fasshauer M, Tonjes A, Schon MR, Kovacs P, Stumvoll M \& Bluher M 2008 Inverse relationship between obesity and FTO gene expression in visceral adipose tissue in humans. Diabetologia 51 641-647.

Livak KJ \& Schmittgen TD 2001 Analysis of relative gene expression data using real-time quantitative PCR and the $2 \mathrm{~T}$ method. Methods $\mathbf{2 5}$ 402-408. 
Lopez-Bermejo A, Petry CJ, Diaz M, Sebastiani G, de Zegher F, Dunger DB \& Ibanez L 2008 The association between the FTO gene and fat mass in humans develops by the postnatal age of two weeks. Journal of Clinical Endocrinology and Metabolism 93 1501-1505.

Masuzaki H, Paterson J, Shinyama H, Morton NM, Mullins JJ, SeckI JR \& Flier JS 2001 A transgenic model of visceral obesity and the metabolic syndrome. Science $2942166-2170$.

McMillen IC \& Robinson JS 2005 Developmental origins of the metabolic syndrome: prediction, plasticity, and programming. Physiological Reviews 85 571-633.

McMillen IC, Muhlhausler BS, Duffield JA \& Yuen BS 2004 Prenatal programming of postnatal obesity: fetal nutrition and the regulation of leptin synthesis and secretion before birth. Proceedings of the Nutrition Society 63 405-412.

McMillen IC, Adam CL \& Muhlhausler BS 2005 Early origins of obesity: programming the appetite regulatory system. Journal of Physiology $\mathbf{5 6 5}$ 9-17.

Mostyn A, Sebert SP, Litten JC, Perkins KS, Laws J, Symonds ME \& Clarke L 2006 Influence of porcine genotype on the abundance of thyroid hormones and leptin in sow milk and its impact on growth, metabolism and expression of key adipose tissue genes in the offspring. Journal of Endocrinology 190 631-639.

O'Rahilly S \& Farooqi IS 2008 Human obesity: a heritable neurobehavioral disorder that is highly sensitive to environmental conditions. Diabetes $\mathbf{5 7}$ 2905-2910.

Price RA, Li WD \& Zhao H 2008 FTO gene SNPs associated with extreme obesity in cases, controls and extremely discordant sister pairs. BMC Medical Genetics 94.

Sahu A 2008 Effects of chronic central leptin infusion on proopiomelanocortin and neurotensin gene expression in the rat hypothalamus. Neuroscience Letters 440 125-129.

Sanchez-Pulido L \& Andrade-Navarro MA 2007 The FTO (fat mass and obesity associated) gene codes for a novel member of the non-heme dioxygenase superfamily. BMC Biochemistry 823.

Sebert SP, Lecannu G, Kozlowski F, Siliart B, Bard JM, Krempf M \& Champ MM 2005 Childhood obesity and insulin resistance in a Yucatan mini-piglet model: putative roles of IGF-1 and muscle PPARs in adipose tissue activity and development. International Journal of Obesity 29 324-333.

Sebert SP, Hyatt MA, Chan LL, Patel N, Bell RC, Keisler D, Stephenson T, Budge H, Symonds ME \& Gardner DS 2009 Maternal nutrient restriction between early-to-mid gestation and its impact upon appetite regulation following juvenile obesity. Endocrinology 150 634-641.

Sellayah D, Sek K, Anthony FW, Watkins AJ, Osmond C, Fleming TP, Hanson MA \& Cagampang FR 2008 Appetite regulatory mechanisms and food intake in mice are sensitive to mismatch in diets between pregnancy and postnatal periods. Brain Research 1237 146-152.

Sharkey D, Gardner DS, Fainberg HP, Wilson V, Sebert S, Bos P, Bell R, Symonds ME \& Budge H 2009 Maternal nutrient restriction during pregnancy differentially alters the unfolded protein response in adipose and renal tissue of obese juvenile offspring. FASEB Journal 23 1314-1324.

Shoulders CC 2008 The FTO (fat mass and obesity-associated) gene: big in adipocyte lipolysis? Journal of Lipid Research 49 495-496.

Stratigopoulos G, Padilla SL, LeDuc CA, Watson E, Hattersley AT, McCarthy MI, Zeltser LM, Chung WK \& Leibel RL 2008 Regulation of Fto/Ftm gene expression in mice and humans. American Journal of Physiology. Regulatory, Integrative and Comparative Physiology 294 R1185-R1196.

Symonds ME, Budge H, Stephenson T \& Gardner DS 2005 Leptin, fetal nutrition, and long-term outcomes for adult hypertension. Endothelium $1273-79$.

Tan JT, Dorajoo R, Seielstad M, Sim XL, Ong RT, Chia KS, Wong TY, Saw SM, Chew SK, Aung T et al. 2008 FTO variants are associated with obesity in the Chinese and Malay populations in Singapore. Diabetes $\mathbf{5 7}$ 2851-2857.
Teng CC, Tjoa S, Fennessey PV, Wilkening RB \& Battaglia FC 2002 Transplacental carbohydrate and sugar alcohol concentrations and their uptakes in ovine pregnancy. Experimental Biology and Medicine 227 189-195.

Teske JA, Levine AS, Kuskowski M, Levine JA \& Kotz CM 2006 Elevated hypothalamic orexin signaling, sensitivity to orexin A, and spontaneous physical activity in obesity-resistant rats. American Journal of Physiology. Regulatory, Integrative and Comparative Physiology 291 R889-R899.

Timpson NJ, Emmett PM, Frayling TM, Rogers I, Hattersley AT, McCarthy MI \& Davey Smith G 2008 The fat mass- and obesityassociated locus and dietary intake in children. American Journal of Clinical Nutrition 88 971-978.

Vickers MH, Gluckman PD, Coveny AH, Hofman PL, Cutfield WS, Gertler A, Breier BH \& Harris M 2008 The effect of neonatal leptin treatment on postnatal weight gain in male rats is dependent on maternal nutritional status during pregnancy. Endocrinology 149 1906-1913.

Villalobos-Comparan $M$, Teresa Flores-Dorantes $M$, Teresa VillarrealMolina M, Rodriguez-Cruz M, Garcia-Ulloa AC, Robles L, HuertasVazquez A, Saucedo-Villarreal N, Lopez-Alarcon M, Sanchez-Munoz F et al. 2008 The FTO gene is associated with adulthood obesity in the Mexican population. Obesity 16 2296-2301.

Wahlen K, Sjolin E \& Hoffstedt J 2008 The common rs9939609 gene variant of the fat mass- and obesity-associated gene FTO is related to fat cell lipolysis. Journal of Lipid Research 49 607-611.

Wardle J, Carnell S, Haworth CM, Farooqi IS, O'Rahilly S \& Plomin R 2008 Obesity associated genetic variation in FTO is associated with diminished satiety. Journal of Clinical Endocrinology and Metabolism 93 3640-3643.

Wardle J, Llewellyn C, Sanderson S \& Plomin R 2009 The FTO gene and measured food intake in children. International Journal of Obesity 33 42-45.

Warnes K, Morris MJ, Symonds ME, Phillips ID, Owens JA \& McMillen IC 1998 Effects of gestation, cortisol and maternal undernutrition on hypothalamic neuropeptide $\mathrm{Y}$ mRNA levels in the sheep fetus. Journal of Neuroendocrinology 10 51-57.

Whorwood CB, Firth KM, Budge H \& Symonds ME 2001 Maternal undernutrition during early to midgestation programs tissue-specific alterations in the expression of the glucocorticoid receptor, 11 betahydroxysteroid dehydrogenase isoforms, and type 1 angiotensin ii receptor in neonatal sheep. Endocrinology 142 2854-2864.

Willers SM, Wijga AH, Brunekreef B, Kerkhof $M$, Gerritsen J, Hoekstra MO, de Jongste JC \& Smit HA 2008 Maternal food consumption during pregnancy and the longitudinal development of childhood asthma. American Journal of Respiratory and Critical Care Medicine 178 124-131.

Williams PJ, Kurlak LO, Perkins AC, Budge H, Stephenson T, Keisler D, Symonds ME \& Gardner DS 2007 Hypertension and impaired renal function accompany juvenile obesity: the effect of prenatal diet. Kidney International 72 279-289.

Zabena C, Gonzalez-Sanchez JL, Martinez-Larrad MT, Torres-Garcia A, Alvarez-Fernandez-Represa J, Corbaton-Anchuelo A, Perez-Barba M \& Serrano-Rios M 2009 The FTO obesity gene. Genotyping and gene expression analysis in morbidly obese patients. Obesity Surgery 19 87-95.

Received 29 April 2009

First decision 5 June 2009

Revised manuscript received 15 September 2009

Accepted 28 September 2009 